\title{
The activity of Nef on HIV-1 infectivity
}

\author{
Stéphane Basmaciogullari ${ }^{1,2}$ * and Massimo Pizzato ${ }^{3}$ \\ ${ }^{1}$ Hôpital Necker-Enfants Malades, Sorbonne Paris Cité, Université Paris Descartes, Paris, France \\ 2 INSERM U845, Paris, France \\ ${ }^{3}$ Centre for Integrative Biology, University of Trento, Trento, Italy
}

\section{Edited by:}

Nadine Laguette, Centre National de la Recherche Scientifique, France

\section{Reviewed by:}

Sarah Rowland-Jones, Weatherall Institute of Molecular Medicine-John Radcliffe Hospital, UK

Michael Schindler, Helmholtz Zentrum

München-German Research Center for Environmental Health, Germany

\section{${ }^{*}$ Correspondence:}

Stéphane Basmaciogullari, INSERM

U845, Bâtiment Lériche, Porte 9,

4ème étage, 98 Rue Didot, 75014

Paris, France

e-mail: stephane.basmaciogullari@

gmail.com;

Massimo Pizzato, Centre for

Integrative Biology, University of

Trento, Via delle Regole 101, 38123

Mattarello, Trento, Italy

e-mail:massimo.pizzato@unitn.it
The replication and pathogenicity of lentiviruses is crucially modulated by "auxiliary proteins" which are expressed in addition to the canonical retroviral ORFs gag, pol, and env. Strategies to inhibit the activity of such proteins are often sought and proposed as possible additions to increase efficacy of the traditional antiretroviral therapy. This requires the acquisition of an in-depth knowledge of the molecular mechanisms underlying their function. The Nef auxiliary protein is expressed uniquely by primate lentiviruses and plays an important role in virus replication in vivo and in the onset of AIDS. Among its several activities Nef enhances the intrinsic infectivity of progeny virions through a mechanism which remains today enigmatic. Here we review the current knowledge surrounding such activity and we discuss its possible role in HIV biology.

Keywords: HIV, AIDS, auxiliary proteins, Nef, retrovirus infectivity

\section{A BRIEF HISTORY OF THE DISCOVERY OF THE Nef ORF}

The first reports of the entire HIV-1 genome sequences exposed an ORF, partially overlapping with the $3^{\prime} \mathrm{LTR}$, which was initially named 3'ORF (Ratner et al., 1985; Sanchez-Pescador et al., 1985). Early studies demonstrated that its gene product was antigenic during the course of natural infection (Arya and Gallo, 1986; Franchini et al., 1986). However, it took several years before its role in vivo and its molecular functions began to be understood. Initial studies suggested that $3^{\prime}$ ORF encoded for a GTPase (Guy et al., 1987), a finding soon dismissed as a possible consequence of sample contamination with bacterial GTPases (Backer et al., 1991). Subsequent reports suggested that $3^{\prime} \mathrm{ORF}$ was a negative factor (hence the name nef, still in use today), because its over-expression was found to attenuate viral transcription and HIV replication in cell culture (Luciw et al., 1987; Ahmad and Venkatesan, 1988; Niederman et al., 1989). These findings were soon contradicted by later reports (Hammes et al., 1989; Kim et al., 1989) which attributed the negative effect to the LTR sequences maintained in Nef-encoding vectors and interfering with HIV gene expression.

The first evidence demonstrating the requirement for an intact nef allele in the maintenance of high viral load and the timely development of immunodeficiency came from Rhesus macaques infected with a mutated strain of SIVmac 239 lacking the Nef ORF (Kestler et al., 1991). Further evidence came from patients who contracted infection with Nef-deleted viruses and manifested long-lasting low level of virus replication and delayed onset of the disease (Deacon et al., 1995; Kirchhoff et al., 1995). A positive effect of Nef on HIV-1 replication was eventually confirmed in vitro using primary cell cultures and, to a lesser extent, in transformed cell lines (Terwilliger et al., 1991; de Ronde et al., 1992; Zazopoulos and Haseltine, 1993; Miller et al., 1994; Spina et al., 1994).

\section{OVERVIEW OF Nef ACTIVITIES}

The nefgene is only present in the genomes of primate lentiviruses, i.e., HIV-1, HIV-2, and SIV. It is translated from a multiply spliced mRNA which generates a protein of 27-32 KDa highly expressed from the early stages of the infection process. Based on crystal (Lee et al., 1996; Arold et al., 1997; Grzesiek et al., 1997) and NMR (Grzesiek et al., 1996, 1997) structures, we know that Nef is made of a globular core domain flanked by a flexible $\mathrm{N}$-terminal arm and a C-terminal disordered loop. Residues crucial for the interaction with different host factors are located in all three regions of the protein. Nef is myristoylated, which contributes to its association with membranes, together with a stretch of basic aminoacids close to the N-terminus (Bentham et al., 2006). Indeed, a significant fraction of Nef is observed in association with the plasma membrane and perinuclear membrane complexes (Kohleisen et al., 1992; Fujii et al., 1996; Greenberg et al., 1997). Myristoylation may also contribute to prevent Nef from multimerizing (Breuer et al., 2006). The protein is also detected within virion particles (Pandori et al., 1996; Welker et al., 1996, 1998; Bukovsky et al., 1997), a feature which could depend on the ability of Nef to associate with cellular membranes. Packaged Nef has also been reported to undergo cleavage by the viral protease (Bukovsky et al., 1997; Chen et al., 1998). However, as discussed below, the meaning and the specificity of Nef packaging into virions remain unclear.

Perhaps the most remarkable feature of Nef is its multifunctionality. Nef does not contain enzymatic activity, but exerts 
several cellular functions resulting from its ability to interact with numerous host factors. The most characterized activities of Nef result from the ability of the protein to connect with the cellular vesicular trafficking machinery and to perturb cell signaling.

\section{MODULATION OF CELL-SURFACE MOLECULES EXPRESSION LEVELS}

Nef interacts with several proteins implicated in intracellular trafficking and modulates cell surface expression of several molecules (Landi et al., 2011). Nef down-regulates CD4 (Garcia and Miller, 1991) by enhancing its uptake into the endosome-lysosome compartment (Aiken et al., 1994; Chowers et al., 1994; Rhee and Marsh, 1994; Schwartz etal., 1995a; Bresnahan et al., 1998; Craig et al., 1998; Piguet et al., 1998, 1999; Janvier et al., 2001; Faure et al., 2004), a function conserved and maintained throughout disease progression that increases both virus infectivity and replication, as discussed in Section "Potential Effect of Nef During Virus Biogenesis."

Nef affects the trafficking of many other proteins, which favors virus replication in the host by hiding or protecting infected cells from immune surveillance and by promoting virus dissemination. Because these properties are not strictly related to the ability of $\mathrm{Nef}$ to increase virus infectivity, they are mentioned in this chapter but the underlying mechanism will not be discussed further.

The ability of Nef to prevent the elimination of infected cells by the immune system is an important feature that favors virus dissemination in the host. Nef down-regulates molecules of the major histocompatibility complex-I (MHC-I; Schwartz et al., 1996) through a still debated mechanism distinct from that involved in CD4 down-regulation (Piguet et al., 2000; Blagoveshchenskaya et al., 2002; Williams et al., 2002, 2005; Larsen et al., 2004; Roeth et al., 2004; Lubben et al., 2007; Noviello et al., 2008; Dikeakos et al., 2012). This protects infected cells against killing by cytotoxic T cells (Collins et al., 1998), and is maintained under strong selective pressure only during the acute phase of infection, when the host is still fully immunocompetent (Carl et al., 2001). Protection against cell lysis is further achieved by Nef-dependent FasL upregulation which triggers apoptosis of bysander cytotoxic cells (Xu et al., 1997, 1999). Of note, HIV and SIV Nef also interfere with MHC-II functions by down-regulating MHC-II complexes and up-regulating the MHC-II-associated II invariant chain (Schindler et al., 2003).

Cell infection by HIV or SIV is also characterized by T-cell receptor (TCR) pathway dysfunction. Nef can down-regulate the TCR/CD3 complex (Bell et al., 1998; Schaefer et al., 2000; Munch et al., 2002), a property restricted to alleles derived from SIV isolates non-pathogenic to their natural host, which might explain the higher virulence of HIV compared with SIV (Schindler et al., 2006). In addition, TCR activity can also be inhibited by the Nef-dependent down-regulation of the co-stimulatory molecule CD28 (Bell et al., 2001; Swigut et al., 2001). Finally, SIV Nef downregulates the restriction factor BST-2 and ensures efficient release of viral particles from infected cells (Jia et al., 2009).

Key to these activities of Nef is the ability to form ternary complexes with cargo molecules and adaptor or coatamer complexes via a ExxLL acidic di-leucin motif (Aiken et al., 1994) a EE diacidic sequence located in its C-terminal loop (Piguet et al., 1999), a EEEE acidic cluster (Piguet et al., 2000) and a $\mathrm{Yxx} \Phi$ motif (where $\Phi$ represents a hydrophobic residue) on its N-terminal arm (Lock et al., 1999).

\section{MODULATION OF T-CELL ACTIVATION}

In addition to modulating receptor expression levels, Nef also hijacks signaling pathways and alters the activation threshold of lymphocytes (Baur et al., 1994; Alexander et al., 1997; Schrager and Marsh, 1999; Simmons et al., 2001) by interacting with Src family tyrosine kinases (Saksela et al., 1995), members of the p21-activated serine/threonine kinases (Sawai et al., 1994, 1996; Khan etal., 1998; Renkema etal., 1999; Agopian etal., 2006) and Vav (Fackler etal., 1999; Rauch et al., 2008). This leads to a transcriptional program resembling that triggered by TCR stimulation, which might create a favorable intracellular milieu for virus replication. Signaling perturbation by Nef also results in the inactivation of cofilin, which inhibits cytoskeleton rearrangement and cell motility (Stolp et al., 2009). Features of the Nef protein, which are reported to contribute to this activity, include a PxxP proline-rich motif (Saksela et al., 1995), an amphipathic $\alpha$-helix in the N-terminal arm (Baur et al., 1997) and a hydrophobic surface within the C-terminal loop (Agopian et al., 2006). Given that Nef increases cell-free virus infectivity in non-T-cell systems, the effect on primary T-cell activation does not seem to correlate with the activity of Nef on virus infectivity.

\section{THE EFFECT OF Nef ON RETROVIRUS INFECTIVITY}

With the term infectivity we here indicate the efficiency with which the virus establishes an infection event within a cell, which culminates with the integration of the virus genome into the host cell genome. This is therefore a parameter which does not depend on steps of the virus life cycle which follow integration, such as virus gene expression or virus release. Infectivity is measured by relating the number or the frequency of the infectious events produced by cell-free virus with the physical number of virus particles. To compare infectivity across different samples, infectious events are therefore normalized to the physical virus content in the inoculum, determined by quantifying the amount of p24 CA protein or the RT-activity of the virus. Most studies investigating HIV-1 infectivity employ infection assays limited to a single round of viral replication by using trans-complemented molecular clones or by the addition of AZT or entry inhibitors at various time points following infection with replication competent viruses, in order to avoid the contributions from successive rounds of replication to the overall phenotype. Steps of the virus life cycle where the effect of Nef on infectivity can be manifest include receptor interaction, entry, uncoating, reverse transcription, nuclear import and integration.

The Guatelli lab was the first to report that HIV-1 lacking the ability to express Nef has lower infectivity compared with the Nefpositive counterpart (Chowers et al., 1994). This observation has then been confirmed by several labs using a variety of experimental systems differing for producer cell type, target cells and viral molecular clones (Aiken and Trono, 1995; Goldsmith et al., 1995; Miller et al., 1995; Tokunaga et al., 1998; Khan et al., 2001; Tobiume et al., 2001; Papkalla et al., 2002). Altogether, the magnitude by which Nef alters HIV-1 infectivity is highly variable, 
ranging from 3 to 40 . In particular, the infectivity of Nef-defective HIV-1 seems to be the most impaired when virus is produced from lymphoid cell lines (Pizzato, 2010).

Additional observations indicate that the effect of Nef on infectivity plays a major function in the biology of primate lentiviruses. First, a comprehensive analysis including nef alleles derived from a large panel of diverse HIV and SIV isolates has demonstrated that the activity on infectivity is phylogenetically highly conserved (Munch et al., 2007). Second, functional analysis of nef alleles obtained during different stages of HIV infection revealed that the Nef effect on infectivity is maintained by a strong selective pressure during disease progression (Carl et al., 2001). Although this evidence suggests an important function for the Nef effect on infectivity, its precise role during the pathogenic infection remains to be deciphered. While an increased virus infectivity would logically imply an advantage on virus replication and therefore on viral load, clear evidence demonstrating such a link remains elusive.

\section{THE EFFECT OF Nef ON VIRUS REPLICATION}

A positive effect of Nef on virus replication was first observed more than 20 years ago (Kim et al., 1989) and remains today mechanistically unclear. While the role of Nef for efficient virus replication in vivo is evident, this is not always the case in spreading infection in vitro, for which the effect of Nef is highly variable depending on the experimental system. The most robust requirement for Nef was observed using primary T-cells or macrophages infected before mitogenic stimulation of the cultures (Miller et al., 1994; Spina et al., 1994). An important contribution to this effect could therefore stem from the ability of Nef to alter T-cell activation status and favor preliminary virus replication before massive stimulation following exposure to mitogens.

In contrast, Nef seems to only have a modest effect on the replication of HIV-1 in transformed cell lines and in activated primary human T-cells. Discrepancy is observed between the marked effect of Nef on the infectivity of single round infection competent viruses and the modest Nef requirement for virus replication in the same cell cultures (Haller et al., 2011). One major difference between single round infections using cell-free virus and spreading infection of HIV throughout a cell culture is that in the latter cell-associated virus can be transmitted directly from cell to cell (cell-to-cell transfer; Jolly et al., 2004) which seems to be remarkably efficient [up to 1000-fold more efficient than cell-free virus (Sourisseau et al., 2007)]. A recent report indicates that Nef exerts only a modest positive effect on cell-to-cell transfer using both transformed cell lines and activated primary cells (Malbec et al., 2013), therefore overriding bigger differences from the contribution of cell-free virus (Haller et al., 2011). The role of the effect of Nef on infectivity on virus replication remains therefore to be elucidated.

\section{THE MECHANISTIC DETAILS OF THE EFFECT OF Nef ON INFECTIVITY}

The effect of Nef on virus infectivity requires its expression in producer cells rather than target cells (Aiken and Trono, 1995). Nef might thus play a role as a virus-borne protein when virions hit target cells. Alternatively, in the presence of Nef, progeny virus particles might inherit a modification which is required to maintain their full infectious potential. Two sides of the same coin should therefore be considered. (1) What is the nature of the Nef-dependent modification inherited by the virus particle and how is it acquired? (2) In which step of the virus life cycle (ranging from receptor interaction to integration) is the infection of a target cell affected by such Nef-dependent modification? (Figure 1).

\section{INFECTIVITY: IS VIRUS-BORNE Nef DOING IT ITSELF?}

Conflicting results have been published regarding the effect of Nef on fusion/entry which will be discussed later (Zhou and Aiken, 2001; Tobiume et al., 2003; Cavrois et al., 2004). Nevertheless the literature agrees that $\mathrm{Nef}+$ viruses complete post-entry steps more efficiently than their Nef- counterparts (Aiken and Trono, 1995; Chowers et al., 1995; Schwartz et al., 1995b). The fact that Nef is incorporated into viral particles and cleaved by HIV-1 protease at residues $\mathrm{W}_{57} \mathrm{~L}_{58}$ in the course of virion maturation makes it reasonable to hypothesize a specific role for virus-borne Nef in early steps of viral replication (Pandori et al., 1996; Welker etal., 1996; Bukovsky etal., 1997). Site-directed mutagenesis led to the identification of molecular species with a range of phenotype regarding their incorporation and maturation in virions; however, no correlation could be drawn between incorporation/maturation and infectivity because mutants were also deficient in other known functions of Nef, mostly CD4 or MHC down-regulation (Bukovsky et al., 1997; Miller et al., 1997; Chen et al., 1998; Welker et al., 1998; Bentham et al., 2006). The fact that Nef can be also incorporated into MLV particles (without affecting virus infectivity) further suggests that it is passively and "unpurposely" incorporated into enveloped virions due to its association with cell membranes (Bukovsky et al., 1997). Two papers by Laguette et al. (2009a) and Qi and Aiken (2008) addressed the question of Nef incorporation and its correlation to infectivity by fusing WT Nef proteins with a "viral carrier protein", Vpr and CypA, respectively. These results support the idea that a role of Nef in the course of virus biogenesis, not as a virus-borne factor, likely accounts for its effect on virus infectivity, and are in line with the inability of Nef to complement the infectivity of Nef- viruses when it is expressed in target cells (Aiken and Trono, 1995; Pizzato et al., 2008).

\section{POTENTIAL EFFECT OF Nef DURING VIRUS BIOGENESIS}

One of the first effects attributed to Nef is its ability to downregulate cell surface CD4 expression level in infected cells (Guy et al., 1987). Because CD4 is the primary receptor for HIV (Dalgleish etal., 1984; Klatzmann et al., 1984), its down-regulation from the plasma membrane spares cells from cytotoxic superinfection and favors virus dissemination (Benson et al., 1993; Little et al., 1994). Furthermore CD4 down-regulation prevents the formation of CD4/gp120 complexes in intracellular compartments and at the plasma membrane, which has been shown to interfere with envelope glycoproteins (Env) incorporation into nascent virions and to decrease virus infectivity (Lama et al., 1999; Cortes et al., 2002; Arganaraz et al., 2003; Lundquist et al., 2004; Schiavoni etal., 2004). This phenotype appears to be of particular importance for primate lentiviruses since HIV and SIV Nef alleles, but also Vpu and Env, down-regulate cell surface CD4 through distinct mechanisms (Garcia and Miller, 1991; Benson et al., 1993; 


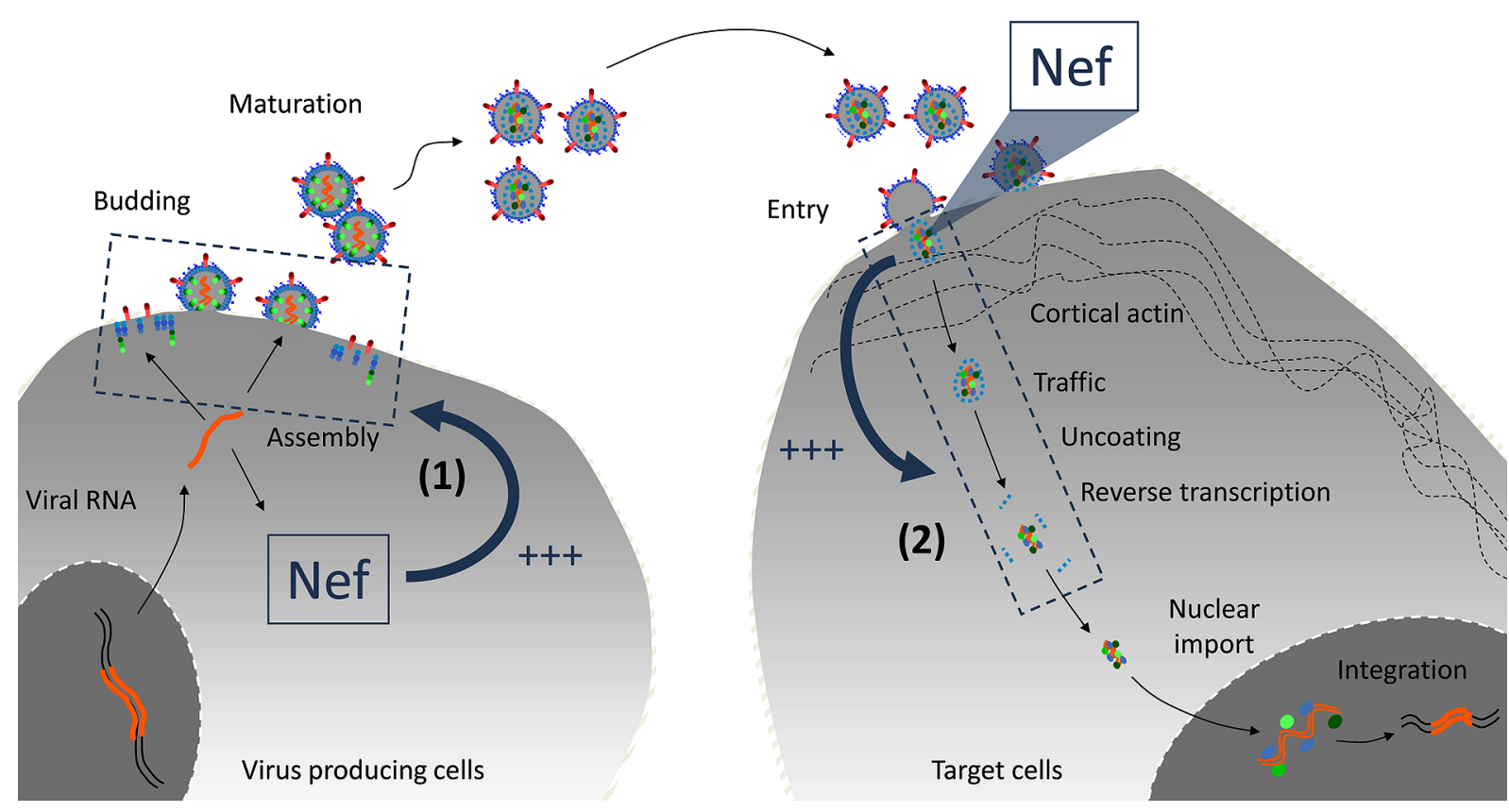

FIGURE 1 | Cellular or virus-borne: localization of Nef activity on virus infectivity. Nef is expressed in infected cells and incorporated into virions. Given the profound imprint of Nef on the biology of infected cells, it may regulate a cellular function in virus-producing cells that favors virus
Sanfridson et al., 1994; Chen et al., 1996; Fujita et al., 1997; Hua and Cullen, 1997; Margottin et al., 1998; Schubert et al., 1998; Wildum et al., 2006; Laguette et al., 2009b; Magadan et al., 2010). CD4 down-regulation by Nef thus seems to favor HIV infectivity and replication as correlated by the Aiken and Kirchhoff groups (Glushakova et al., 2001; Lundquist et al., 2002). However, the sole ability of Nef to down-regulate CD4 cannot explain its effect on virus infectivity since Nef remains capable of increasing virus infectivity when virions are produced from CD4-negative cells or when virions are pseudotyped with the MLV-A envelope glycoprotein that does not interact with CD4 (Aiken and Trono, 1995; Miller et al., 1995; Aiken, 1997; Pizzato et al., 2008). In addition, Nef does not seem to modulate Env incorporation into the viral membrane when virions are produced from CD4-negative cells (Miller etal., 1995; Lai et al., 2011). The effect on infectivity is therefore an independent activity of Nef.

The hypothesis of a role of Nef in the course of virus biogenesis was further investigated in a comparative proteomic analysis of WT and Nef-defective NL4-3 viral particles intended to identify differences in their composition that might explain the higher infectivity of WT viruses (Bregnard et al., 2013). This study revealed that Ezrin and EHD4 are more abundant in Nef-defective than in WT NL4-3 virions but failed to demonstrate a direct inhibitory effect of these virus-borne proteins on Nef-defective virus infectivity. On the contrary, Ezrin and EHD4 depletion decreased WT viruses infectivity but not that of Nef-defective viruses, which supports their roles as possible co-factors in the Nef-mediated increase of virus infectivity. A similar comparative analysis has been conducted to identify a specific signature of Nef on the lipid composition of the viral membrane (Brugger et al., 2007). Although differences could be identified between Nef+ and Nef-derived membranes, none was found to account for the Nef-dependent increase of virus infectivity. Nef-dependent posttranslational modification of viral proteins could also account for the higher infectivity of Nef + over Nef- viruses. Although Nef-associated kinases were found to induce matrix phosphorylation on serine residues (Swingler et al., 1997), matrix was later found dispensable not only for virus replication, but also for Nef responsiveness, which ruled out its contribution to the phenotype (Reil et al., 1998; Dorfman et al., 2002). Of note, matrix deletion from Gag requires mutation or deletion of HIV-1 Env cytoplasmic tail to ensure the incorporation of the retroviral glycoprotein into the viral membrane and the biogenesis of infectious virions (Ono et al., 1997; Reil et al., 1998; Murakami and Freed, 2000; Ono et al., 2000; Tedbury et al., 2013). Simultaneous mutations might thus interfere and hide the requirement for matrix phosphorylation in the Nef-dependent increase of virus infectivity. Further investigation is thus required to formally identify Nef-dependent modifications of viral proteins, or incorporation/exclusion of cellular factors into/from virions, that might directly affect virus infectivity.

\section{EFFECT OF Nef (OR MODIFICATIONS INHERITED FROM PRODUCER CELLS) IN TARGET CELLS}

Although Nef does not seem to affect the concentration of Env on the virus surface, its ability to increase virus infectivity is somewhat dependent on the mechanism that promotes fusion between the virus and the cell membrane and was long thought to be linked 
to the route of viral entry. While Nef increases the infectivity of viruses decorated with Env that allow for fusion at neutral $\mathrm{pH}$ such as that of HIV and A-MLV (referred to as responsive Env), no effect of Nef is observed with Env that requires virus endocytosis and endosome acidification to promote fusion such as that of VSV and RSV-A (Miller et al., 1995; Aiken, 1997; Luo et al., 1998; Pizzato et al., 2008). This has suggested the existence of a post-entry block encountered by incoming capsids when fusion takes place at the plasma membrane and counteracted by Nef (or its effects inherited from the virus producing cell, see below) or bypassed by incoming virions traveling through the endocytic network, out of reach of cytoplasmic factors. The cortical actin network has been suggested to account for such post-entry block, based on the relieving effect of actin-targeting drugs on the poorly infectious Nef- viruses but not on the fully infectious Nef+ viruses (Campbell et al., 2004). However, although Nef increases the infectivity of HIV-1, regardless of its tropism for CXCR4 or CCR5 receptors, not all HIV-1 Envs are equally responsive to Nef (Chazal et al., 2001; Papkalla et al., 2002; Lai et al., 2011; Usami and Gottlinger, 2013). Furthermore, the correlation between Nef responsiveness and entry at the plasma membrane is at odds with evidence of HIV entry into target cells in early endosomes, after endocytic vesicles have passed the cortical actin network but before endosome acidification (Miyauchi et al., 2009; van Wilgenburg et al., 2014). In addition, Nef responsiveness can be observed even when fusion takes place in acidic endosomes, in experimental setting where cells express RSV-A Env and virions are pseudotyped with the cognate Tva receptor (Pizzato et al., 2008).

Nef might thus have an effect on fusion that correlates neither with the route of entry, nor with Env dependence on $\mathrm{pH}$. Such effect has been investigated with responsive and non-responsive Envs and led to contradictory results. While a Nef-dependent increase of the fusion process extrapolated from virus/cell or intravirion fusion assays has been reported by some groups (Schaeffer et al., 2001; Zhou and Aiken, 2001), others have failed to detect any difference between Nef + and Nef- viruses in the completion of the fusion step, including groups that used the most quantitative $\beta$ lam-Vpr fusion assay developed in the Greene laboratory (Miller et al., 1995; Tobiume et al., 2003; Campbell et al., 2004; Cavrois et al., 2004; Basmaciogullari, personal communication). Such conflicting results led Cavrois et al. (2004) to cautiously interpret the sensitivity of the $\beta$ lam-Vpr assay and the hypothetical effect of Nef on fusion. The authors suggested that Nef might assist the enlargement of the pore arising from the fusion between the virus and cell membranes, and promote translocation of the viral capsid into the cell cytoplasm. Small pores arising from the fusion between Nef- viruses and cell membranes would restrict capsid translocation but allow for full diffusion of the fluorogenic substrate or Blam-Vpr. This would explain why Nef- viruses are less infectious than Nef+ viruses yet induce identical $\beta$ lam-Vpr readouts. However, this model is based on the assumption that pore size does not limit substrate or Blam-Vpr diffusion, which needs to be demonstrated. Alternatively, if small pores restrict diffusion, hence $\beta$ lam-Vpr positivity, identical $\beta$ lam-Vpr readouts obtained with Nef + and Nef- viruses can only be achieved if large pores are underrepresented and have a negligible contribution to the overall $\beta$ lam-Vpr signal (i.e. Nef+ viruses: $99 \%$ small pores and 1\% large pores/full entry; Nef- viruses, 99.9\% small pores and $0.1 \%$ large pores/full entry). The fact that fusion inhibitors clearly decrease infectivity and the Vpr- $\beta$ lam signal does not support this hypothesis. It thus seems that the most likely explanation for identical $\beta$ lam-Vpr readouts is that Nef has no effect on fusion/capsid delivery but affects post-fusion steps of the virus life cycle. Of Note, Day et al. (2004), who also used this assay, reported a fusion advantage of Nef+ viruses over Nefviruses, which highlights the need for a more robust and sensitive fusion assay in order to clarify the possible effect of Nef on fusion.

Besides these discrepancies on fusion, it has been shown that Nef affects the accessibility of neutralizing antibodies directed against the MPER region of gp41 in a cell/virus fusion context (Lai et al., 2011). Although this did not fully correlate with the ability of Nef to increase virus infectivity, it nevertheless demonstrates that Nef might affect Env proteins conformation or the lipid environment adjacent to the MPER region and thus the fusion capacity of Env glycoproteins. The difference between responsive and nonresponsive HIV-1 Env was recently mapped to an epitope within the V2 region of gp120 (Usami and Gottlinger, 2013). Yet, given the divergence between Nef responsive HIV-1 and MLV-A Env glycoprotein sequences and the responsiveness of Tva-pseudotyped viruses (Pizzato et al., 2008), the common parameter that allows for Nef responsiveness remains unknown. It thus seems that proteins found on the virus surface that mediate fusion, whether they be viral Envs or cognate receptor(s), are major determinants of Nef responsiveness but most likely not through their role in fusion.

The effect of Nef has also been documented at the level of cDNA synthesis in target cells. Although early experiments could not discriminate between effects of Nef on fusion or post-fusion steps, they nevertheless demonstrated that Nef + viruses generate more early reverse transcription products than Nef- viruses, supporting an effect of Nef operating anywhere between fusion and viral DNA translocation to the nucleus (Aiken and Trono, 1995; Schwartz et al., 1995b). Of note, intravirion stimulation of reverse transcription was shown to compensate for the effect of Nef on virus infectivity (Khan etal., 2001). Given the interdependence between uncoating and RT, these results suggest that Nef might assist either of the mechanisms (Hulme et al., 2011; Yang et al., 2013). Although Nef does not show any effect on uncoating in vitro, an effect of Nef in vivo cannot be ruled out (Forshey and Aiken, 2003).

\section{CONVERGING MECHANISMS}

Three papers published recently describe a striking parallel between HIV-1 Nef and MLV glycoGag (Pizzato, 2010; Usami and Gottlinger, 2013; Usami et al., 2014). This protein arises from the translation of the unspliced MLV RNA from a CUG initiation codon upstream from the conventional initiation codon of Gag, which results in the addition of 88 residues in frame and $\mathrm{N}$ terminal to Gag, responsible for the type II orientation of the corresponding protein where the added $\mathrm{N}$ terminal residues constitute the transmembrane domain and extend into the cytoplasm of the cell. It has been shown that ectopic expression of Nef or glycoGag similarly increases the infectivity of viruses produced from cells transfected with a Nef- provirus. Interestingly, simultaneous co-expression 
of Nef and glycoGag has no synergistic effect and glycoGag has no effect on VSV-G pseudotyped viruses, suggesting that these proteins are involved in the same mechanism that eventually leads to the increase of virus infectivity (Pizzato, 2010). In addition the V2 region of HIV-1 Env, which dictates Nef responsiveness, also dictates responsiveness to glycoGag (Usami and Gottlinger, 2013). Finally, although the ability of Nef to increase virus infectivity and its effect on the accessibility of MPER epitopes on HIV-1 Env partially overlap, glycoGag expression also affects the accessibility of similar MPER epitopes (Lai et al., 2011). This further confirms the converging functions of these unrelated proteins.

\section{MECHANISTIC HYPOTHESES THE BROAD PICTURE}

Several hypotheses can be put forward in a two-act scenario responsible for the differential infectivity of Nef+ and Nefviruses. Nef might hijack cellular pathways in virus-producing cells that ultimately optimize infectivity (modification of viral proteins or viral content beyond its known elements). Cellular pathways in target cells might then specifically assist Nef+ viruses in the early steps of the virus life cycle (Figures 2A,C). Both sides of this same coin can then either involve cofactors recruited by Nef or inhibitory factors counteracted by Nef. So far, the lentiviral auxiliary proteins Vif, $\mathrm{VpU}$, and $\mathrm{VpX}$ have been involved in the neutralization of an inhibitory factor (or restriction factor) such as Apobec3, Bst2, and SAMHD1. In the case of Nef both possibilities remain open. The Nef requirement for reaching optimal infectivity is highly variable and depends on the cell types from which virions are produced (Pizzato, 2010), it is thus plausible that such variability is conferred by differential expression of one or more cellular genes involved in the scenario depicted above.

\section{WHAT IS Nef DOING TO THE VIRUS, HOW AND WHERE?}

Comparative analysis of Nef+ and Nef- viral particles have clearly revealed differences in the lipid and protein composition, confirming that Nef expression in virus-producing cells has an impact on the virus biogenesis. Although the modification of the viral lipid bilayer by Nef did not seem to account for the higher infectivity of Nef+ viruses over Nef- viruses, further investigation with more sensitive fusion assays that are yet to be developed might reveal a direct link between the viral membrane lipid composition, membrane fusion and infectivity. Differences in the protein composition of viral particles also revealed partial depletion or enrichment in particular proteins, depending on the expression of Nef in virus-producing cells. Ezrin and EHD4 were found in higher concentration in Nef- viruses and their involvement in the infectivity phenotype confirmed; however, their relative excess did not seem to account for the poor infectivity of Nef- viruses. Rather, it was interpreted that Ezrin and EHD4 are hijacked by Nef in the process of increasing virus infectivity, thus preventing their passive incorporation into virions.
A

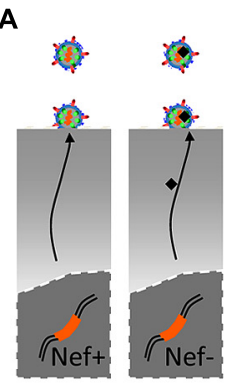

D

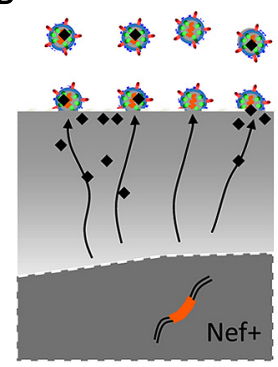

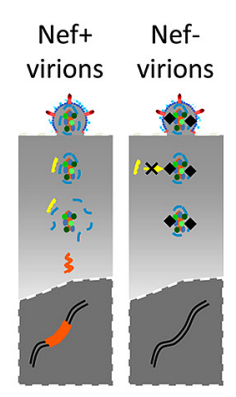

B

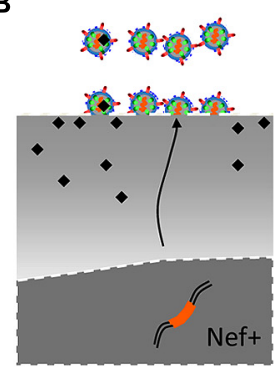

E

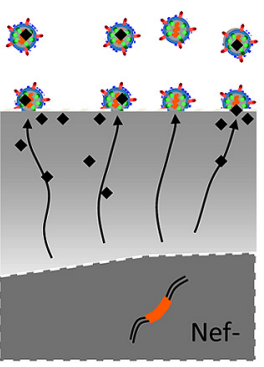

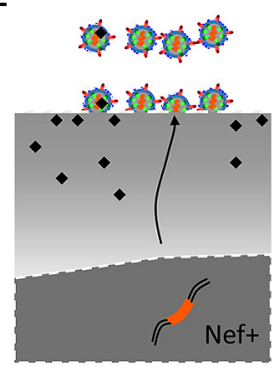
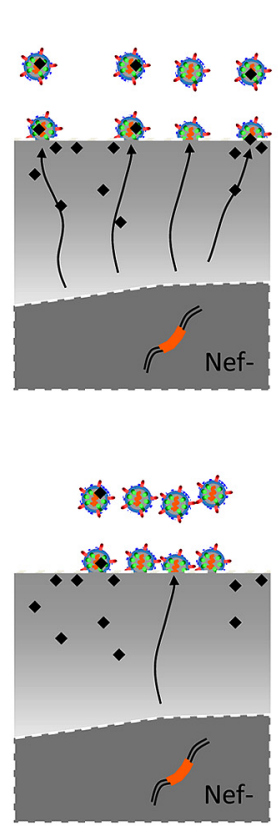

C

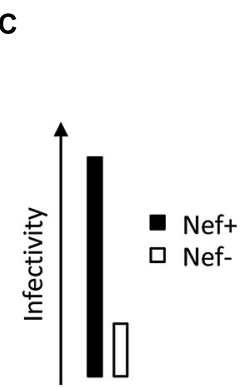

$\mathbf{F}$

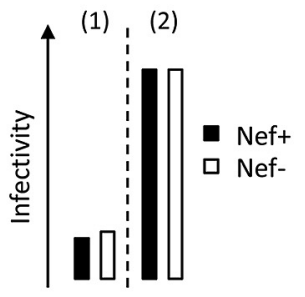

FIGURE 2 | Possible mechanisms responsible for the differential infectivity of Nef+ and Nef- viruses. (A), Nef- virions may acquire a defect during biogenesis which could be either the packaging of an inhibitor into virions (black shape), or the exclusion of a cofactor (not shown). This defect might then prevent the recruitment of cofactor (yellow shape) or be the target of an inhibitor (not shown) in target cells. (B,C) The effect of Nef on virus infectivity is evident when virus is produced from Nef-responsive cells, in which Nef regulates such inhibitor or promote virus assembly to subcellular locations where the defect is not acquired (B). (D-F) In contrast, Nef-non-responsive producer cells generate Nef+ and Nef- viruses with similar infectivities (F). Two possibilities may explain this phenotype: Nef fails to protect the virus from the defect $[\mathbf{D}, \mathbf{F}(\mathbf{1})$, Virions have suboptimal infectivity even in the presence of Nef]; alternatively, producer cells lack the cause of the defect or target virus assembly away from inhibitors $[\mathbf{E}, \mathbf{F}(2)$, Nef- virus already has optimal infectivity]. 
It is interesting to note the converging phenotype of the nef- mutation and mutations of $\mathrm{p} 24 \mathrm{CA}$ on serine residues: both mutants are poorly infectious but their infectivity is restored by VSV-G pseudotyping (Brun et al., 2008). Although this is far from explaining how Nef increases virus infectivity, it nevertheless confirms that post-translational modification by Nef is an interesting line of investigation to follow. Additional work is thus required in order to identify the differences between Nef + and Nef- responsible for the differential behavior of viruses when they hit target cells.

As presented in this review, a main functional feature which characterizes Nef alleles and is required for several Nef activities, is the ability to intersect with the vesicular trafficking machinery of the cell. As we discussed earlier, Nef is capable of interacting with AP1, AP2, and $\beta \mathrm{COP} 1$ via distinct and discrete motifs present in HIV and SIV Nef molecules (ExxxLL, EE, EEEE, YxxL). Many observations converge toward a fundamental role of vesicular trafficking for the activity of Nef for infectivity. In particular: (1) HIV-1 Nef requires the integrity of the AP2 interacting motif ExxxLL in virus producing cells (Chowers et al., 1994). (2) Similarly, SIV Nef requires the YxxL motif (Lock et al., 1999). (3) Mutant HIV-1 Nef proteins, which do not interact with dynamin 2 (crucial for intracellular vesicles biogenesis), are no longer capable of increasing HIV infectivity (Pizzato et al., 2007). (4) The activity of Nef on infectivity requires functional clathrinmediated endocytosis, because it is impaired by silencing clathrin gene expression and by over-expressing transdominant-negative dynamin 2 and AP180. (Pizzato et al., 2007). (5) Glycogag requires and interacts with AP2 via a YxxL motif to rescue the infectivity of Nef-defective HIV-1 (Usami et al., 2014). 5) EHD4 and Ezrin silencing render $\mathrm{Nef}+$ viruses as poorly infectious as $\mathrm{Nef}-$ viruses (Bregnard et al., 2013).

As highlighted earlier, doubts remain on the possibility that Nef affects cytoplasmic delivery of HIV. In the hypothesis where Nef enhances the efficiency of fusion between the virus and the cell membranes, it might do so by promoting the endocytosis of a membrane-bound fusion inhibitor in virus producing cells otherwise incorporated into viral membrane. More generally, factors with potential inhibitory effect, or responsible for the recruitment of co-factors in target cells, might also be rerouted away from or to the viral assembly platforms through the deregulation of protein trafficking by Nef in infected cells.

Another interesting challenge is the identification of the cellular compartment where $\mathrm{Nef}+$ virions acquire their phenotype. Nef might drive the viral components to the appropriate assembly platforms where virions acquire specific features responsible for their higher infectivity and, as suggested earlier, the nature of the protein that decorates virions might play a role in this sorting mechanism, independently of their involvement in membrane fusion. Despite some flexibility in virus pseudotyping, much evidence suggests that the acquisition of Env by budding virions is somewhat regulated (Johnson et al., 1998; Jorgenson et al., 2009; Muranyi et al., 2013; Roy et al., 2013). Env might be targeted by Nef and rerouted to ensure assembly at specific sites (Figure 2B). Of note, similar infectivities of Nef- and Nef + viruses might either reflect the inability of Nef to drive virus assembly to such compartments (Figures 2D,F) or indicate that optimal assembly does not require the presence of Nef (Figures 2E,F). Because cytoplasmic tail-deleted Envs are still Nef responsive, specific determinants might lie in the extracellular domain, and interact with a chaperone along its secretion and delivery to the plasma membrane. Although this awaits formal evidence, it is compatible with the recent identification of a V2 region in HIV-1 Env as a major determinant of responsiveness to Nef/glycoGag.

\section{CONSEOUENCES IN TARGET CELLS}

Tracking virions in target cells is particularly challenging, especially when virions cannot be pseudotyped with VSV-G. For this reason, not much is known about possible functions of virusborne molecules in early steps of the life cycle. Whether Nef itself or the modifications it brings to viral particles impact on the completion of early steps, this most likely relies on the recruitment of co-factors or the neutralization of inhibitory factors in target cells. A cutting edge genetic approach based on the screening of a human siRNA library has allowed for the identification of cellular factors that modulate HIV-1 replication (HDFs, HIV-1 dependency factors). However, virions used in such HTS were either Nef- or VSV-G pseudotyped, excluding de facto the possibility to identify HDFs involved in the ability of Nef to increase virus infectivity (Brass et al., 2008; Konig et al., 2008; Zhou et al., 2008). A similar screening performed in experimental settings where $\mathrm{Nef}+$ and Nef- viruses could be compared such as that described by Bregnard et al. (2013), would shed light on the pathways usurped by Nef to increase virus infectivity.

\section{CONCLUSION}

Biochemistry-based approaches have been used in order to identify cellular factors involved in the many functions of Nef. Affinity tagging or immunoprecipitation followed by mass spectrometry (Pizzato et al., 2007; Jager et al., 2012; Mukerji et al., 2012) and conventional or ubiquitin-split yeast two-hybrid screening (Benichou et al., 1997; Kammula et al., 2012) have identified Nef binding partners. Omics methods have also been used to identify how HIV infection or Nef expression alone modifies the biology of the cell (Schrager and Marsh, 1999; Wang et al., 2000; Simmons et al., 2001; Kramer-Hammerle et al., 2005; van't Wout et al., 2005; Berro et al., 2007; Ringrose et al., 2008; Kramer et al., 2012). Given the many Nef partners and cellular processes affected by Nef identified so far, a strategy focused on the analysis of viral particles might better address the question of the effect of Nef on virus infectivity. Mass-spectrometry based techniques and computing tools have strikingly improved, which makes possible the analysis of Nef-induced post-translational modification of HIV-1 proteins in order to reveal specific differences between Nef + and Nef- virions. In addition, due to the convergence of Nef and glycoGag on the infectivity phenotype, comparing the results of experiments carried out with these proteins might narrow down the list of modifications relevant for virus infectivity.

\section{ACKNOWLEDGMENTS}

For this work, Stéphane Basmaciogullari received support from Sidaction and Agence Nationale de la Recherche sur le SIDA et les Hepatites Virales (ANRS), and Massimo Pizzato from FP7 Marie Curie Career Integration Grant nr. 322130. 


\section{REFERENCES}

Agopian, K., Wei, B. L., Garcia, J. V., and Gabuzda, D. (2006). A hydrophobic binding surface on the human immunodeficiency virus type $1 \mathrm{Nef}$ core is critical for association with p21-activated kinase 2. J. Virol. 80, 3050-3061. doi: 10.1128/JVI.80.6.3050-3061.2006

Ahmad, N., and Venkatesan, S. (1988). Nef protein of HIV-1 is a transcriptional repressor of HIV-1 LTR. Science 241, 1481-1485. doi: 10.1126/science.3262235

Aiken, C. (1997). Pseudotyping human immunodeficiency virus type 1 (HIV-1) by the glycoprotein of vesicular stomatitis virus targets HIV-1 entry to an endocytic pathway and suppresses both the requirement for Nef and the sensitivity to cyclosporin A. J. Virol. 71, 5871-5877.

Aiken, C., Konner, J., Landau, N. R., Lenburg, M. E., and Trono, D. (1994). Nef induces CD4 endocytosis: requirement for a critical dileucine motif in the membrane-proximal CD4 cytoplasmic domain. Cell 76, 853-864. doi: 10.1016/0092-8674(94)90360-3

Aiken, C., and Trono, D. (1995). Nef stimulates human immunodeficiency virus type 1 proviral DNA synthesis. J. Virol. 69, 5048-5056.

Alexander, L., Du, Z., Rosenzweig, M., Jung, J. U., and Desrosiers, R. C. (1997). A role for natural simian immunodeficiency virus and human immunodeficiency virus type 1 nef alleles in lymphocyte activation. J. Virol. 71, 6094-6099.

Arganaraz, E. R., Schindler, M., Kirchhoff, F., Cortes, M. J., and Lama, J. (2003). Enhanced CD4 down-modulation by late stage HIV-1 nef alleles is associated with increased Env incorporation and viral replication. J. Biol. Chem. 278, 3391233919. doi: 10.1074/jbc.M303679200

Arold, S., Franken, P., Strub, M. P., Hoh, F., Benichou, S., Benarous, R., et al. (1997) The crystal structure of HIV-1 Nef protein bound to the Fyn kinase SH3 domain suggests a role for this complex in altered T cell receptor signaling. Structure 5, 1361-1372. doi: 10.1016/S0969-2126(97)00286-4

Arya, S. K., and Gallo, R. C. (1986). Three novel genes of human T-lymphotropic virus type III: immune reactivity of their products with sera from acquired immune deficiency syndrome patients. Proc. Natl. Acad. Sci. U.S.A. 83, 2209-2213. doi: 10.1073/pnas.83.7.2209

Backer, J. M., Mendola, C. E., Fairhurst, J. L., and Kovesdi, I. (1991). The HIV-1 nef protein does not have guanine nucleotide binding, GTPase, or autophosphorylating activities. AIDS Res. Hum. Retroviruses 7, 1015-1020. doi: 10.1089/aid.1991.7.1015

Baur, A. S., Sass, G., Laffert, B., Willbold, D., Cheng-Mayer, C., and Peterlin, B. M. (1997). The N-terminus of Nef from HIV-1/SIV associates with a protein complex containing Lck and a serine kinase. Immunity 6, 283-291. doi: 10.1016/S10747613(00)80331-3

Baur, A. S., Sawai, E. T., Dazin, P., Fantl, W. J., Cheng-Mayer, C., and Peterlin, B. M. (1994). HIV-1 Nef leads to inhibition or activation of T cells depending on its intracellular localization. Immunity 1, 373-384. doi: 10.1016/1074-7613(94)90068-X

Bell, I., Ashman, C., Maughan, J., Hooker, E., Cook, F., and Reinhart, T. A. (1998). Association of simian immunodeficiency virus Nef with the T-cell receptor (TCR) zeta chain leads to TCR down-modulation. J. Gen. Virol. 79(Pt 11), 2717-2727.

Bell, I., Schaefer, T. M., Trible, R. P., Amedee, A., and Reinhart, T. A. (2001). Down-modulation of the costimulatory molecule, CD28, is a conserved activity of multiple SIV Nefs and is dependent on histidine 196 of Nef. Virology 283, 148-158. doi: 10.1006/viro.2001.0872

Benichou, S., Liu, L. X., Erdtmann, L., Selig, L., and Benarous, R. (1997). Use of the two-hybrid system to identify cellular partners of the HIV1 Nef protein. Res. Virol. 148, 71-73. doi: 10.1016/S0923-2516(97)81918-8

Benson, R. E., Sanfridson, A., Ottinger, J. S., Doyle, C., and Cullen, B. R. (1993). Downregulation of cell-surface CD4 expression by simian immunodeficiency virus Nef prevents viral super infection. J. Exp. Med. 177, 1561-1566. doi: 10.1084/jem.177.6.1561

Bentham, M., Mazaleyrat, S., and Harris, M. (2006). Role of myristoylation and Nterminal basic residues in membrane association of the human immunodeficiency virus type 1 Nef protein. J. Gen. Virol. 87, 563-571. doi: 10.1099/vir.0.81200-0

Berro, R., De La Fuente, C., Klase, Z., Kehn, K., Parvin, L., Pumfery, A., et al. (2007). Identifying the membrane proteome of HIV-1 latently infected cells. J. Biol. Chem. 282, 8207-8218. doi: 10.1074/jbc.M606324200

Blagoveshchenskaya, A. D., Thomas, L., Feliciangeli, S. F., Hung, C. H., and Thomas, G. (2002). HIV-1 Nef downregulates MHC-I by a PACS-1- and PI3K-regulated ARF6 endocytic pathway. Cell 111, 853-866. doi: 10.1016/S0092-8674(02) 01162-5
Brass, A. L., Dykxhoorn, D. M., Benita, Y., Yan, N., Engelman, A., Xavier, R. J., et al. (2008). Identification of host proteins required for HIV infection through a functional genomic screen. Science 319, 921-926. doi: 10.1126/science.1152725

Bregnard, C., Zamborlini, A., Leduc, M., Chafey, P., Camoin, L., Saib, A., et al. (2013). Comparative proteomic analysis of HIV-1 particles reveals a role for Ezrin and EHD4 in the Nef-dependent increase of virus infectivity. J. Virol. 87, 3729-3740. doi: 10.1128/JVI.02477-12

Bresnahan, P. A., Yonemoto, W., Ferrell, S., Williams-Herman, D., Geleziunas, R., and Greene, W. C. (1998). A dileucine motif in HIV-1 Nef acts as an internalization signal for CD4 downregulation and binds the AP-1 clathrin adaptor. Curr. Biol. 8, 1235-1238. doi: 10.1016/S0960-9822(07)00517-9

Breuer, S., Gerlach, H., Kolaric, B., Urbanke, C., Opitz, N., and Geyer, M. (2006). Biochemical indication for myristoylation-dependent conformational changes in HIV-1 Nef. Biochemistry 45, 2339-2349. doi: 10.1021/bi052052c

Brugger, B., Krautkramer, E., Tibroni, N., Munte, C. E., Rauch, S., Leibrecht, I., et al. (2007). Human immunodeficiency virus type $1 \mathrm{Nef}$ protein modulates the lipid composition of virions and host cell membrane microdomains. Retrovirology 4:70. doi: 10.1186/1742-4690-4-70

Brun, S., Solignat, M., Gay, B., Bernard, E., Chaloin, L., Fenard, D., et al. (2008). VSV-G pseudotyping rescues HIV-1 CA mutations that impair core assembly or stability. Retrovirology 5:57. doi: 10.1186/1742-4690-5-57

Bukovsky, A. A., Dorfman, T., Weimann, A., and Gottlinger, H. G. (1997). Nef association with human immunodeficiency virus type 1 virions and cleavage by the viral protease. J. Virol. 71, 1013-1018.

Campbell, E. M., Nunez, R., and Hope, T. J. (2004). Disruption of the actin cytoskeleton can complement the ability of Nef to enhance human immunodeficiency virus type 1 infectivity. J. Virol. 78, 5745-5755. doi: 10.1128/JVI.78.11.5745-5755.2004 Carl, S., Greenough, T. C., Krumbiegel, M., Greenberg, M., Skowronski, J., Sullivan, J. L., et al. (2001). Modulation of different human immunodeficiency virus type 1 Nef functions during progression to AIDS. J. Virol. 75, 3657-3665. doi: 10.1128/JVI.75.8.3657-3665.2001

Cavrois, M., Neidleman, J., Yonemoto, W., Fenard, D., and Greene, W. C. (2004). $\mathrm{HIV}-1$ virion fusion assay: uncoating not required and no effect of Nef on fusion. Virology 328, 36-44. doi: 10.1016/j.virol.2004.07.015

Chazal, N., Singer, G., Aiken, C., Hammarskjold, M. L., and Rekosh, D. (2001). Human immunodeficiency virus type 1 particles pseudotyped with envelope proteins that fuse at low $\mathrm{pH}$ no longer require Nef for optimal infectivity. J. Virol. 75, 4014-4018. doi: 10.1128/JVI.75.8.4014-4018.2001

Chen, B. K., Gandhi, R. T., and Baltimore, D. (1996). CD4 down-modulation during infection of human $\mathrm{T}$ cells with human immunodeficiency virus type 1 involves independent activities of vpu, env, and nef. J. Virol. 70, 6044-6053.

Chen, Y. L., Trono, D., and Camaur, D. (1998). The proteolytic cleavage of human immunodeficiency virus type $1 \mathrm{Nef}$ does not correlate with its ability to stimulate virion infectivity. J. Virol. 72, 3178-3184.

Chowers, M. Y., Pandori, M. W., Spina, C. A., Richman, D. D., and Guatelli, J. C. (1995). The growth advantage conferred by HIV-1 nef is determined at the level of viral DNA formation and is independent of CD4 downregulation. Virology 212, 451-457. doi: 10.1006/viro.1995.1502

Chowers, M. Y., Spina, C. A., Kwoh, T. J., Fitch, N. J., Richman, D. D., and Guatelli, J. C. (1994). Optimal infectivity in vitro of human immunodeficiency virus type 1 requires an intact nef gene. J. Virol. 68, 2906-2914.

Collins, K. L., Chen, B. K., Kalams, S. A., Walker, B. D., and Baltimore, D. (1998). HIV-1 Nef protein protects infected primary cells against killing by cytotoxic $\mathrm{T}$ lymphocytes. Nature 391, 397-401. doi: 10.1038/34929

Cortes, M. J., Wong-Staal, F., and Lama, J. (2002). Cell surface CD4 interferes with the infectivity of HIV-1 particles released from T cells. J. Biol. Chem. 277, 1770-1779. doi: 10.1074/jbc.M109807200

Craig, H. M., Pandori, M. W., and Guatelli, J. C. (1998). Interaction of HIV-1 Nef with the cellular dileucine-based sorting pathway is required for CD4 downregulation and optimal viral infectivity. Proc. Natl. Acad. Sci. U.S.A. 95, 1122911234. doi: 10.1073/pnas.95.19.11229

Dalgleish, A. G., Beverley, P. C., Clapham, P. R., Crawford, D. H., Greaves, M. F., and Weiss, R. A. (1984). The CD4 (T4) antigen is an essential component of the receptor for the AIDS retrovirus. Nature 312, 763-767. doi: 10.1038/312763a0

Day, J. R., Munk, C., and Guatelli, J. C. (2004). The membrane-proximal tyrosinebased sorting signal of human immunodeficiency virus type $1 \mathrm{gp} 41$ is required for optimal viral infectivity. J. Virol. 78, 1069-1079. doi: 10.1128/JVI.78.3.10691079.2004 
Deacon, N. J., Tsykin, A., Solomon, A., Smith, K., Ludford-Menting, M., Hooker, D. J., et al. (1995). Genomic structure of an attenuated quasi species of HIV1 from a blood transfusion donor and recipients. Science 270, 988-991. doi: 10.1126/science.270.5238.988

de Ronde, A., Klaver, B., Keulen, W., Smit, L., and Goudsmit, J. (1992). Natural HIV$1 \mathrm{NEF}$ accelerates virus replication in primary human lymphocytes. Virology 188 391-395. doi: 10.1016/0042-6822(92)90772-H

Dikeakos, J. D., Thomas, L., Kwon, G., Elferich, J., Shinde, U., and Thomas, G. (2012). An interdomain binding site on HIV-1 Nef interacts with PACS-1 and PACS-2 on endosomes to down-regulate MHC-I. Mol. Biol. Cell 23, 2184-2197. doi: 10.1091/mbc.E11-11-0928 mbc.E11-11-0928

Dorfman, T., Popova, E., Pizzato, M., and Gottlinger, H. G. (2002). Nef enhances human immunodeficiency virus type 1 infectivity in the absence of matrix. $J$. Virol. 76, 6857-6862. doi: 10.1128/JVI.76.13.6857-6862.2002

Fackler, O. T., Luo, W., Geyer, M., Alberts, A. S., and Peterlin, B. M. (1999). Activation of Vav by Nef induces cytoskeletal rearrangements and downstream effector functions. Mol. Cell 3, 729-739. doi: 10.1016/S1097-2765(01) 80005-8

Faure, J., Stalder, R., Borel, C., Sobo, K., Piguet, V., Demaurex, N., et al. (2004) ARF1 regulates Nef-induced CD4 degradation. Curr. Biol. 14, 1056-1064. doi: 10.1016/j.cub.2004.06.021

Forshey, B. M., and Aiken, C. (2003). Disassembly of human immunodeficiency virus type 1 cores in vitro reveals association of Nef with the subviral ribonucleoprotein complex. J. Virol. 77, 4409-4414. doi: 10.1128/JVI.77.7.4409-4414.2003

Franchini, G., Robert-Guroff, M., Wong-Staal, F., Ghrayeb, J., Kato, I., Chang, T. W., et al. (1986). Expression of the protein encoded by the $3^{\prime}$ open reading frame of human T-cell lymphotropic virus type III in bacteria: demonstration of its immunoreactivity with human sera. Proc. Natl. Acad. Sci. U.S.A. 83, 5282-5285. doi: 10.1073/pnas.83.14.5282

Fujii, Y., Otake, K., Fujita, Y., Yamamoto, N., Nagai, Y., Tashiro, M., et al. (1996). Clustered localization of oligomeric Nef protein of human immunodeficiency virus type 1 on the cell surface. FEBS Lett. 395, 257-261. doi: 10.1016/00145793(96)01048-4

Fujita, K., Omura, S., and Silver, J. (1997). Rapid degradation of CD4 in cells expressing human immunodeficiency virus type $1 \mathrm{Env}$ and $\mathrm{Vpu}$ is blocked by proteasome inhibitors. J. Gen. Virol. 78(Pt 3), 619-625.

Garcia, J. V., and Miller, A. D. (1991). Serine phosphorylation-independent downregulation of cell-surface CD4 by nef. Nature 350, 508-511. doi: $10.1038 / 350508 \mathrm{a} 0$

Glushakova, S., Munch, J., Carl, S., Greenough, T. C., Sullivan, J. L., Margolis, L., et al. (2001). CD4 down-modulation by human immunodeficiency virus type 1 Nef correlates with the efficiency of viral replication and with CD4(+) T-cell depletion in human lymphoid tissue ex vivo. J. Virol. 75, 10113-10117. doi: 10.1128/JVI.75.21.10113-10117.2001

Goldsmith, M. A., Warmerdam, M. T., Atchison, R. E., Miller, M. D., and Greene W. C. (1995). Dissociation of the CD4 downregulation and viral infectivity enhancement functions of human immunodeficiency virus type $1 \mathrm{Nef}$. J. Virol. $69,4112-4121$

Greenberg, M. E., Bronson, S., Lock, M., Neumann, M., Pavlakis, G. N., and Skowronski, J. (1997). Co-localization of HIV-1 Nef with the AP-2 adaptor protein complex correlates with Nef-induced CD4 down-regulation. EMBO J. 16, 6964-6976. doi: 10.1093/emboj/16.23.6964

Grzesiek, S., Bax, A., Clore, G. M., Gronenborn, A. M., Hu, J. S., Kaufman, J., et al. (1996). The solution structure of HIV-1 Nef reveals an unexpected fold and permits delineation of the binding surface for the $\mathrm{SH} 3$ domain of Hck tyrosine protein kinase. Nat. Struct. Biol. 3, 340-345. doi: 10.1038/nsb0496-340

Grzesiek, S., Bax, A., Hu, J. S., Kaufman, J., Palmer, I., Stahl, S. J., et al. (1997) Refined solution structure and backbone dynamics of HIV-1 Nef. Protein Sci. 6 , 1248-1263. doi: 10.1002/pro.5560060613

Guy, B., Kieny, M. P., Riviere, Y., Le Peuch, C., Dott, K., Girard, M., et al. (1987). HIV $\mathrm{F} / 3^{\prime}$ orf encodes a phosphorylated GTP-binding protein resembling an oncogene product. Nature 330, 266-269. doi: 10.1038/330266a0

Haller, C., Tibroni, N., Rudolph, J. M., Grosse, R., and Fackler, O. T. (2011). Nef does not inhibit F-actin remodelling and HIV-1 cell-cell transmission at the T lymphocyte virological synapse. Eur. J. Cell Biol. 90, 913-921. doi: 10.1016/j.ejcb.2010.09.010

Hammes, S. R., Dixon, E. P., Malim, M. H., Cullen, B. R., and Greene, W. C. (1989). Nef protein of human immunodeficiency virus type 1: evidence against its role as a transcriptional inhibitor. Proc. Natl. Acad. Sci. U.S.A. 86, 9549-9553. doi: 10.1073/pnas.86.23.9549

Hua, J., and Cullen, B. R. (1997). Human immunodeficiency virus types 1 and 2 and simian immunodeficiency virus Nef use distinct but overlapping target sites for downregulation of cell surface CD4. J. Virol. 71, 6742-6748.

Hulme, A. E., Perez, O., and Hope, T. J. (2011). Complementary assays reveal a relationship between HIV-1 uncoating and reverse transcription. Proc. Natl. Acad. Sci. U.S.A. 108, 9975-9980. doi: 10.1073/pnas.1014522108

Jager, S., Cimermancic, P., Gulbahce, N., Johnson, J. R., Mcgovern, K. E., Clarke, S. C., et al. (2012). Global landscape of HIV-human protein complexes. Nature 481, 365-370. doi: 10.1038/nature10719

Janvier, K., Craig, H., Le Gall, S., Benarous, R., Guatelli, J., Schwartz, O., et al. (2001). Nef-induced CD4 downregulation: a diacidic sequence in human immunodeficiency virus type 1 Nef does not function as a protein sorting motif through direct binding to beta-COP. J. Virol. 75, 3971-3976. doi: 10.1128/JVI.75.8.3971-3976.2001

Jia, B., Serra-Moreno, R., Neidermyer, W., Rahmberg, A., Mackey, J., Fofana, I. B., etal. (2009). Species-specific activity of SIV Nef and HIV-1 Vpu in overcoming restriction by tetherin/BST2. PLoS Pathog. 5:e1000429. doi: 10.1371/journal.ppat.1000429

Johnson, J. E., Rodgers, W., and Rose, J. K. (1998). A plasma membrane localization signal in the HIV-1 envelope cytoplasmic domain prevents localization at sites of vesicular stomatitis virus budding and incorporation into VSV virions. Virology 251, 244-252. doi: 10.1006/viro.1998.9429

Jolly, C., Kashefi, K., Hollinshead, M., and Sattentau, Q. J. (2004). HIV-1 cell to cell transfer across an Env-induced, actin-dependent synapse. J. Exp. Med. 199, 283-293. doi: 10.1084/jem.20030648

Jorgenson, R. L., Vogt, V. M., and Johnson, M. C. (2009). Foreign glycoproteins can be actively recruited to virus assembly sites during pseudotyping. J. Virol. 83, 4060-4067. doi: 10.1128/JVI.02425-08

Kammula, E. C., Motter, J., Gorgels, A., Jonas, E., Hoffmann, S., and Willbold, D. (2012). Brain transcriptome-wide screen for HIV-1 Nef protein interaction partners reveals various membrane-associated proteins. PLoS ONE 7:e51578. doi: 10.1371/journal.pone.0051578

Kestler, H. W. III, Ringler, D. J., Mori, K., Panicali, D. L., Sehgal, P. K., Daniel, M. D., et al. (1991). Importance of the nef gene for maintenance of high virus loads and for development of AIDS. Cell 65, 651-662. doi.org/10.1016/0092-8674(91) 90097-I

Khan, I. H., Sawai, E. T., Antonio, E., Weber, C. J., Mandell, C. P., Montbriand, P., et al. (1998). Role of the SH3-ligand domain of simian immunodeficiency virus Nef in interaction with Nef-associated kinase and simian AIDS in rhesus macaques. J. Virol. 72, 5820-5830.

Khan, M., Garcia-Barrio, M., and Powell, M. D. (2001). Restoration of wild-type infectivity to human immunodeficiency virus type 1 strains lacking nef by intravirion reverse transcription. J. Virol. 75, 12081-12087. doi: 10.1128/JVI.75.24.12081-12087.2001

Kim, S., Ikeuchi, K., Byrn, R., Groopman, J., and Baltimore, D. (1989). Lack of a negative influence on viral growth by the nef gene of human immunodeficiency virus type 1. Proc. Natl. Acad. Sci. U.S.A. 86, 9544-9548. doi: 10.1073/pnas.86.23. 9544

Kirchhoff, F., Greenough, T. C., Brettler, D. B., Sullivan, J. L., and Desrosiers, R. C. (1995). Brief report: absence of intact nef sequences in a long-term survivor with nonprogressive HIV-1 infection. N. Engl. J. Med. 332, 228-232. doi: 10.1056/NEJM199501263320405

Klatzmann, D., Champagne, E., Chamaret, S., Gruest, J., Guetard, D., Hercend, T., et al. (1984). T-lymphocyte T4 molecule behaves as the receptor for human retrovirus LAV. Nature 312, 767-768. doi: 10.1038/312767a0

Kohleisen, B., Neumann, M., Herrmann, R., Brack-Werner, R., Krohn, K. J., Ovod, V., et al. (1992). Cellular localization of Nef expressed in persistently HIV-1-infected low-producer astrocytes. AIDS 6, 1427-1436. doi: 10.1097/00002030-19921200000002

Konig, R., Zhou, Y., Elleder, D., Diamond, T. L., Bonamy, G. M., Irelan, J. T., et al. (2008). Global analysis of host-pathogen interactions that regulate early-stage HIV-1 replication. Cell 135, 49-60. doi: 10.1016/j.cell.2008.07.032

Kramer-Hammerle, S., Hahn, A., Brack-Werner, R., and Werner, T. (2005). Elucidating effects of long-term expression of HIV-1 Nef on astrocytes by microarray, promoter, and literature analyses. Gene 358, 31-38. doi: 10.1016/j.gene.2005. 05.011 
Kramer, G., Moerland, P. D., Jeeninga, R. E., Vlietstra, W. J., Ringrose, J. H., Byrman, C., et al. (2012). Proteomic analysis of HIV-T cell interaction: an update. Front. Microbiol. 3:240. doi: 10.3389/fmicb.2012.00240

Laguette, N., Benichou, S., and Basmaciogullari, S. (2009a). HIV-1 Nef Incorporation into Virions does not Increase Infectivity. J. Virol. 83, 1093-1104. doi: 10.1128/JVI.01633-08

Laguette, N., Bregnard, C., Bouchet, J., Benmerah, A., Benichou, S., and Basmaciogullari, S. (2009b). Nef-induced CD4 endocytosis in human immunodeficiency virus type 1 host cells: role of the p56lck kinase. J. Virol. 83, 7117-7128. doi: 10.1128/JVI.01648-08

Lai, R. P., Yan, J., Heeney, J., Mcclure, M. O., Gottlinger, H., Luban, J., et al. (2011). Nef decreases HIV-1 sensitivity to neutralizing antibodies that target the membrane-proximal external region of TMgp41. PLoS Pathog. 7:e1002442. doi: 10.1371/journal.ppat.1002442

Lama, J., Mangasarian, A., and Trono, D. (1999). Cell-surface expression of CD4 reduces HIV-1 infectivity by blocking Env incorporation in a Nef- and Vpuinhibitable manner. Curr. Biol. 9, 622-631. doi: 10.1016/S0960-9822(99)80284-X

Landi, A., Iannucci, V., Nuffel, A. V., Meuwissen, P., and Verhasselt, B. (2011). One protein to rule them all: modulation of cell surface receptors and molecules by HIV Nef. Curr. HIV Res. 9, 496-504. doi: 10.2174/157016211798842116

Larsen, J. E., Massol, R. H., Nieland, T. J., and Kirchhausen, T. (2004). HIV Nef-mediated major histocompatibility complex class I down-modulation is independent of Arf6 activity. Mol. Biol. Cell 15, 323-331. doi: 10.1091/mbc.E0308-0578

Lee, C. H., Saksela, K., Mirza, U. A., Chait, B. T., and Kuriyan, J. (1996). Crystal structure of the conserved core of HIV-1 Nef complexed with a Src family SH3 domain. Cell 85, 931-942. doi: 10.1016/S0092-8674(00)81276-3

Little, S. J., Riggs, N. L., Chowers, M. Y., Fitch, N. J., Richman, D. D., Spina, C. A., et al. (1994). Cell surface CD4 downregulation and resistance to superinfection induced by a defective provirus of HIV-1. Virology 205, 578-582. doi: 10.1006/viro.1994.1683

Lock, M., Greenberg, M. E., Iafrate, A. J., Swigut, T., Muench, J., Kirchhoff, F., et al. (1999). Two elements target SIV Nef to the AP-2 clathrin adaptor complex, but only one is required for the induction of CD4 endocytosis. EMBO J. 18, 2722-2733. doi: 10.1093/emboj/18.10.2722

Lubben, N. B., Sahlender, D. A., Motley, A. M., Lehner, P. J., Benaroch, P., and Robinson, M. S. (2007). HIV-1 Nef-induced down-regulation of MHC class requires AP-1 and clathrin but not PACS-1 and is impeded by AP-2. Mol. Biol. Cell 18, 3351-3365. doi: 10.1091/mbc.E07-03-0218

Luciw, P. A., Cheng-Mayer, C., and Levy, J. A. (1987). Mutational analysis of the human immunodeficiency virus: the orf-B region down-regulates virus replication. Proc. Natl. Acad. Sci. U.S.A. 84, 1434-1438. doi: 10.1073/pnas.84.5.1434

Lundquist, C. A., Tobiume, M., Zhou, J., Unutmaz, D., and Aiken, C. (2002). Nef-mediated downregulation of CD4 enhances human immunodeficiency virus type 1 replication in primary $\mathrm{T}$ lymphocytes. J. Virol. 76, 4625-4633. doi: 10.1128/JVI.76.9.4625-4633.2002

Lundquist, C. A., Zhou, J., and Aiken, C. (2004). Nef stimulates human immunodeficiency virus type 1 replication in primary $\mathrm{T}$ cells by enhancing virion-associated gp120 levels: coreceptor-dependent requirement for Nef in viral replication. $J$. Virol. 78, 6287-6296. doi: 10.1128/JVI.78.12.6287-6296.2004

Luo, T., Douglas, J. L., Livingston, R. L., and Garcia, J. V. (1998). Infectivity enhancement by HIV-1 Nef is dependent on the pathway of virus entry: implications for HIV-based gene transfer systems. Virology 241, 224-233. doi: 10.1006/viro.1997.8966

Magadan, J. G., Perez-Victoria, F. J., Sougrat, R., Ye, Y., Strebel, K., and Bonifacino, J. S. (2010). Multilayered mechanism of CD4 downregulation by HIV-1 Vpu involving distinct ER retention and ERAD targeting steps. PLoS Pathog. 6:e1000869. doi: 10.1371/journal.ppat.1000869

Malbec, M., Sourisseau, M., Guivel-Benhassine, F., Porrot, F., Blanchet, F., Schwartz, O., et al. (2013). HIV-1 Nef promotes the localization of Gag to the cell membrane and facilitates viral cell-to-cell transfer. Retrovirology 10, 80. doi: 10.1186/17424690-10-80

Margottin, F., Bour, S. P., Durand, H., Selig, L., Benichou, S., Richard, V., et al. (1998). A novel human WD protein, h-beta TrCp, that interacts with HIV-1 Vpu connects CD4 to the ER degradation pathway through an F-box motif. Mol. Cell 1, 565-574. doi: 10.1016/S1097-2765(00)80056-8

Miller, M. D., Warmerdam, M. T., Ferrell, S. S., Benitez, R., and Greene, W. C. (1997). Intravirion generation of the C-terminal core domain of HIV-1 Nef by the HIV-1 protease is insufficient to enhance viral infectivity. Virology 234, 215-225. doi: 10.1006/viro.1997.8641

Miller, M. D., Warmerdam, M. T., Gaston, I., Greene, W. C., and Feinberg, M. B. (1994). The human immunodeficiency virus-1 nef gene product: a positive factor for viral infection and replication in primary lymphocytes and macrophages. $J$. Exp. Med. 179, 101-113. doi: 10.1084/jem.179.1.101

Miller, M. D., Warmerdam, M. T., Page, K. A., Feinberg, M. B., and Greene, W. C. (1995). Expression of the human immunodeficiency virus type 1 (HIV-1) nef gene during HIV-1 production increases progeny particle infectivity independently of gp160 or viral entry. J. Virol. 69, 579-584.

Miyauchi, K., Kim, Y., Latinovic, O., Morozov, V., and Melikyan, G. B. (2009). HIV enters cells via endocytosis and dynamin-dependent fusion with endosomes. Cell 137, 433-444. doi: 10.1016/j.cell.2009.02.046

Mukerji, J., Olivieri, K. C., Misra, V., Agopian, K. A., and Gabuzda, D. (2012). Proteomic analysis of HIV-1 Nef cellular binding partners reveals a role for exocyst complex proteins in mediating enhancement of intercellular nanotube formation. Retrovirology 9, 33. doi: 10.1186/1742-4690-9-33

Munch, J., Janardhan, A., Stolte, N., Stahl-Hennig, C., Ten Haaft, P., Heeney, J. L., etal. (2002). T-cell receptor: CD3 down-regulation is a selected in vivo function of simian immunodeficiency virus Nef but is not sufficient for effective viral replication in rhesus macaques. J. Virol. 76, 12360-12364. doi: 10.1128/JVI.76.23.12360-12364.2002

Munch, J., Rajan, D., Schindler, M., Specht, A., Rucker, E., Novembre, F. J., et al. (2007). Nef-mediated enhancement of virion infectivity and stimulation of viral replication are fundamental properties of primate lentiviruses. J. Virol. 81, 1385213864. doi: 10.1128/JVI.00904-07

Murakami, T., and Freed, E. O. (2000). Genetic evidence for an interaction between human immunodeficiency virus type 1 matrix and alpha-helix 2 of the gp41 cytoplasmic tail. J. Virol. 74, 3548-3554. doi: 10.1128/JVI.74.8.3548-3554. 2000

Muranyi, W., Malkusch, S., Muller, B., Heilemann, M., and Krausslich, H. G. (2013). Super-resolution microscopy reveals specific recruitment of HIV-1 envelope proteins to viral assembly sites dependent on the envelope C-terminal tail. PLoS Pathog. 9:e1003198. doi: 10.1371/journal.ppat. 1003198

Niederman, T. M., Thielan, B. J., and Ratner, L. (1989). Human immunodeficiency virus type 1 negative factor is a transcriptional silencer. Proc. Natl. Acad. Sci. U.S.A. 86, 1128-1132. doi: 10.1073/pnas.86.4.1128

Noviello, C. M., Benichou, S., and Guatelli, J. C. (2008). Cooperative binding of the class I major histocompatibility complex cytoplasmic domain and human immunodeficiency virus type $1 \mathrm{Nef}$ to the endosomal AP- 1 complex via its mu subunit. J. Virol. 82, 1249-1258. doi: 10.1128/JVI.00660-07

Ono, A., Huang, M., and Freed, E. O. (1997). Characterization of human immunodeficiency virus type 1 matrix revertants: effects on virus assembly, Gag processing, and Env incorporation into virions. J. Virol. 71, 44094418.

Ono, A., Orenstein, J. M., and Freed, E. O. (2000). Role of the Gag matrix domain in targeting human immunodeficiency virus type 1 assembly. J. Virol. 74, 2855-2866. doi: 10.1128/JVI.74.6.2855-2866.2000

Pandori, M. W., Fitch, N. J., Craig, H. M., Richman, D. D., Spina, C. A., and Guatelli, J. C. (1996). Producer-cell modification of human immunodeficiency virus type 1: Nef is a virion protein. J. Virol. 70, 4283-4290.

Papkalla, A., Munch, J., Otto, C., and Kirchhoff, F. (2002). Nef enhances human immunodeficiency virus type 1 infectivity and replication independently of viral coreceptor tropism. J. Virol. 76, 8455-8459. doi: 10.1128/JVI.76.16.84558459.2002

Piguet, V., Chen, Y. L., Mangasarian, A., Foti, M., Carpentier, J. L., and Trono, D. (1998). Mechanism of Nef-induced CD4 endocytosis: Nef connects CD4 with the mu chain of adaptor complexes. EMBO J. 17, 2472-2481. doi: 10.1093/emboj/17.9.2472

Piguet, V., Gu, F., Foti, M., Demaurex, N., Gruenberg, J., Carpentier, J. L., et al. (1999). Nef-induced CD4 degradation: a diacidic-based motif in Nef functions as a lysosomal targeting signal through the binding of beta-COP in endosomes. Cell 97, 63-73. doi: 10.1016/S0092-8674(00)80715-1

Piguet, V., Wan, L., Borel, C., Mangasarian, A., Demaurex, N., Thomas, G., et al. (2000). HIV-1 Nef protein binds to the cellular protein PACS-1 to downregulate class I major histocompatibility complexes. Nat. Cell Biol. 2, 163-167. doi: $10.1038 / 35004038$ 
Pizzato, M. (2010). MLV glycosylated-Gag is an infectivity factor that rescues Nef-deficient HIV-1. Proc. Natl. Acad. Sci. U.S.A. 107, 9364-9369. doi: 10.1073/pnas.1001554107

Pizzato, M., Helander, A., Popova, E., Calistri, A., Zamborlini, A., Palu, G., et al. (2007). Dynamin 2 is required for the enhancement of HIV-1 infectivity by Nef. Proc. Natl. Acad. Sci. U.S.A. 104, 6812-6817. doi: 10.1073/pnas.0607622104

Pizzato, M., Popova, E., and Gottlinger, H. G. (2008). Nef can enhance the infectivity of receptor-pseudotyped human immunodeficiency virus type 1 particles. J. Virol. 82, 10811-10819. doi: 10.1128/JVI.01150-08

Qi, M., and Aiken, C. (2008). Nef enhances HIV-1 infectivity via association with the virus assembly complex. Virology 373, 287-297. doi: 10.1016/j.virol.2007.12.001

Ratner, L., Haseltine, W., Patarca, R., Livak, K. J., Starcich, B., Josephs, S. F., et al. (1985). Complete nucleotide sequence of the AIDS virus, HTLV-III. Nature 313 , 277-284. doi: 10.1038/313277a0

Rauch, S., Pulkkinen, K., Saksela, K., and Fackler, O. T. (2008). Human immunodeficiency virus type 1 Nef recruits the guanine exchange factor Vavl via an unexpected interface into plasma membrane microdomains for association with p21-activated kinase 2 activity. J. Virol. 82, 2918-2929. doi: 10.1128/JVI.02185-07

Reil, H., Bukovsky, A. A., Gelderblom, H. R., and Gottlinger, H. G. (1998). Efficient HIV-1 replication can occur in the absence of the viral matrix protein. EMBO J. 17, 2699-2708. doi: 10.1093/emboj/17.9.2699

Renkema, G. H., Manninen, A., Mann, D. A., Harris, M., and Saksela, K. (1999). Identification of the Nef-associated kinase as p21-activated kinase 2. Curr. Biol. 9, 1407-1410. doi: 10.1016/S0960-9822(00)80086-X

Rhee, S. S., and Marsh, J. W. (1994). Human immunodeficiency virus type 1 Nefinduced down-modulation of CD4 is due to rapid internalization and degradation of surface CD4. J. Virol. 68, 5156-5163.

Ringrose, J. H., Jeeninga, R. E., Berkhout, B., and Speijer, D. (2008). Proteomic studies reveal coordinated changes in T-cell expression patterns upon infection with human immunodeficiency virus type 1. J. Virol. 82, 4320-4330. doi: 10.1128/JVI.01819-07

Roeth, J. F., Williams, M., Kasper, M. R., Filzen, T. M., and Collins, K. L. (2004). HIV1 Nef disrupts MHC-I trafficking by recruiting AP-1 to the MHC-I cytoplasmic tail. J. Cell Biol. 167, 903-913. doi: 10.1083/jcb.200407031

Roy, N. H., Chan, J., Lambele, M., and Thali, M. (2013). Clustering and mobility of HIV-1 Env at viral assembly sites predict its propensity to induce cell-cell fusion. J. Virol. 87, 7516-7525. doi: 10.1128/JVI.00790-13

Saksela, K., Cheng, G., and Baltimore, D. (1995). Proline-rich (PxxP) motifs in HIV$1 \mathrm{Nef}$ bind to $\mathrm{SH} 3$ domains of a subset of Src kinases and are required for the enhanced growth of Nef+ viruses but not for down-regulation of CD4. EMBO J. 14, 484-491.

Sanchez-Pescador, R., Power, M. D., Barr, P. J., Steimer, K. S., Stempien, M. M., Brown-Shimer, S. L., et al. (1985). Nucleotide sequence and expression of an AIDS-associated retrovirus (ARV-2). Science 227, 484-492. doi: $10.1126 /$ science. 2578227

Sanfridson, A., Cullen, B. R., and Doyle, C. (1994). The simian immunodeficiency virus Nef protein promotes degradation of CD4 in human T cells. J. Biol. Chem. 269, 3917-3920.

Sawai, E. T., Baur, A., Struble, H., Peterlin, B. M., Levy, J. A., and Cheng-Mayer, C. (1994). Human immunodeficiency virus type 1 Nef associates with a cellular serine kinase in T lymphocytes. Proc. Natl. Acad. Sci. U.S.A. 91, 1539-1543. doi: 10.1073/pnas.91.4.1539

Sawai, E. T., Khan, I. H., Montbriand, P. M., Peterlin, B. M., Cheng-Mayer, C., and Luciw, P. A. (1996). Activation of PAK by HIV and SIV Nef: importance for AIDS in rhesus macaques. Curr. Biol. 6, 1519-1527. doi: 10.1016/S09609822(96)00757-9

Schaefer, T. M., Bell, I., Fallert, B. A., and Reinhart, T. A. (2000). The Tcell receptor zeta chain contains two homologous domains with which simian immunodeficiency virus Nef interacts and mediates down-modulation. J. Virol. 74, 3273-3283. doi: 10.1128/JVI.74.7.3273-3283.2000

Schaeffer, E., Geleziunas, R., and Greene, W. C. (2001). Human immunodeficiency virus type 1 Nef functions at the level of virus entry by enhancing cytoplasmic delivery of virions. J. Virol. 75, 2993-3000. doi: 10.1128/JVI.75.6.2993-3000.2001

Schiavoni, I., Trapp, S., Santarcangelo, A. C., Piacentini, V., Pugliese, K., Baur, A., et al. (2004). HIV-1 Nef enhances both membrane expression and virion incorporation of Env products. A model for the Nef-dependent increase of HIV-1 infectivity. J. Biol. Chem. 279, 22996-23006. doi: 10.1074/jbc.M3124 53200
Schindler, M., Munch, J., Kutsch, O., Li, H., Santiago, M. L., BibolletRuche, F., et al. (2006). Nef-mediated suppression of $\mathrm{T}$ cell activation was lost in a lentiviral lineage that gave rise to HIV-1. Cell 125, 1055-1067. doi: 10.1016/j.cell.2006.04.033

Schindler, M., Wurfl, S., Benaroch, P., Greenough, T. C., Daniels, R., Easterbrook, P., et al. (2003). Down-modulation of mature major histocompatibility complex class II and up-regulation of invariant chain cell surface expression are wellconserved functions of human and simian immunodeficiency virus nef alleles. J. Virol. 77, 10548-10556. doi: 10.1128/JVI.77.19.10548-10556.2003

Schrager, J. A., and Marsh, J. W. (1999). HIV-1 Nef increases T cell activation in a stimulus-dependent manner. Proc. Natl. Acad. Sci. U.S.A. 96, 8167-8172. doi: 10.1073/pnas.96.14.8167

Schubert, U., Anton, L. C., Bacik, I., Cox, J. H., Bour, S., Bennink, J. R., et al. (1998). CD4 glycoprotein degradation induced by human immunodeficiency virus type 1 $\mathrm{Vpu}$ protein requires the function of proteasomes and the ubiquitin-conjugating pathway. J. Virol. 72, 2280-2288.

Schwartz, O., Dautry-Varsat, A., Goud, B., Marechal, V., Subtil, A., Heard, J. M., et al. (1995a). Human immunodeficiency virus type 1 Nef induces accumulation of CD4 in early endosomes. J. Virol. 69, 528-533.

Schwartz, O., Marechal, V., Danos, O., and Heard, J. M. (1995b). Human immunodeficiency virus type $1 \mathrm{Nef}$ increases the efficiency of reverse transcription in the infected cell. J. Virol. 69, 4053-4059.

Schwartz, O., Marechal, V., Le Gall, S., Lemonnier, F., and Heard, J. M. (1996). Endocytosis of major histocompatibility complex class I molecules is induced by the HIV-1 Nef protein. Nat. Med. 2, 338-342. doi: $10.1038 / \mathrm{nm} 0$ 396-338

Simmons, A., Aluvihare, V., and Mcmichael, A. (2001). Nef triggers a transcriptional program in $\mathrm{T}$ cells imitating single-signal $\mathrm{T}$ cell activation and inducing HIV virulence mediators. Immunity 14, 763-777. doi: 10.1016/S1074-7613(01) 00158-3

Sourisseau, M., Sol-Foulon, N., Porrot, F., Blanchet, F., and Schwartz, O. (2007). Inefficient human immunodeficiency virus replication in mobile lymphocytes. J. Virol. 81, 1000-1012. doi: 10.1128/JVI.01629-06

Spina, C. A., Kwoh, T. J., Chowers, M. Y., Guatelli, J. C., and Richman, D. D. (1994). The importance of nef in the induction of human immunodeficiency virus type 1 replication from primary quiescent CD4 lymphocytes. J. Exp. Med. 179, 115-123. doi: 10.1084/jem.179.1.115

Stolp, B., Reichman-Fried, M., Abraham, L., Pan, X., Giese, S. I., Hannemann, S., et al. (2009). HIV-1 Nef interferes with host cell motility by deregulation of Cofilin. Cell Host Microbe 6, 174-186. doi: 10.1016/j.chom.2009.06.004

Swigut, T., Shohdy, N., and Skowronski, J. (2001). Mechanism for down-regulation of CD28 by Nef. EMBO J. 20, 1593-1604. doi: 10.1093/emboj/20.7.1593

Swingler, S., Gallay, P., Camaur, D., Song, J., Abo, A., and Trono, D. (1997). The Nef protein of human immunodeficiency virus type 1 enhances serine phosphorylation of the viral matrix. J. Virol. 71, 4372-4377.

Tedbury, P. R., Ablan, S. D., and Freed, E. O. (2013). Global rescue of defects in HIV-1 envelope glycoprotein incorporation: implications for matrix structure. PLoS Pathog. 9:e1003739. doi: 10.1371/journal.ppat.1003739

Terwilliger, E. F., Langhoff, E., Gabuzda, D., Zazopoulos, E., and Haseltine, W. A. (1991). Allelic variation in the effects of the nef gene on replication of human immunodeficiency virus type 1. Proc. Natl. Acad. Sci. U.S.A. 88, 10971-10975. doi: 10.1073/pnas.88.23.10971

Tobiume, M., Lineberger, J. E., Lundquist, C. A., Miller, M. D., and Aiken, C. (2003). Nef does not affect the efficiency of human immunodeficiency virus type 1 fusion with target cells. J. Virol. 77, 10645-10650. doi: 10.1128/JVI.77.19.1064510650.2003

Tobiume, M., Takahoko, M., Tatsumi, M., and Matsuda, M. (2001). Establishment of a MAGI-derived indicator cell line that detects the Nef enhancement of HIV-1 infectivity with high sensitivity. J. Virol. Methods 97, 151-158. doi: 10.1016/S01660934(01)00349-4

Tokunaga, K., Kojima, A., Kurata, T., Ikuta, K., Akari, H., Koyama, A. H., et al. (1998). Enhancement of human immunodeficiency virus type 1 infectivity by Nef is producer cell-dependent. J. Gen. Virol. 79(Pt 10), 24472453.

Usami, Y., and Gottlinger, H. (2013). HIV-1 Nef Responsiveness Is Determined by Env Variable Regions involved in trimer association and correlates with neutralization sensitivity. Cell Rep. 5, 802-812. doi: 10.1016/j.celrep.2013. 09.028 
Usami, Y., Popov, S., and Gottlinger, H. G. (2014). The Nef-Like Effect of Murine Leukemia Virus Glycosylated Gag on HIV-1 infectivity is mediated by its cytoplasmic domain and depends on the AP-2 adaptor complex. J. Virol. 88, 3443-3454. doi: 10.1128/JVI.01933-13

van't Wout, A. B., Swain, J. V., Schindler, M., Rao, U., Pathmajeyan, M. S., Mullins, J. I., et al. (2005). Nef induces multiple genes involved in cholesterol synthesis and uptake in human immunodeficiency virus type 1-infected T cells. J. Virol. 79, 10053-10058. doi: 10.1128/JVI.79.15.10053-10058.2005

van Wilgenburg, B., Moore, M. D., James, W. S., and Cowley, S. A. (2014). The Productive Entry Pathway of HIV-1 in macrophages is dependent on endocytosis through lipid rafts containing CD4. PLoS ONE 9:e86071. doi: 10.1371/journal.pone.0086071

Wang, J. K., Kiyokawa, E., Verdin, E., and Trono, D. (2000). The Nef protein of HIV-1 associates with rafts and primes T cells for activation. Proc. Natl. Acad. Sci U.S.A. 97, 394-399. doi: 10.1073/pnas.97.1.394

Welker, R., Harris, M., Cardel, B., and Krausslich, H. G. (1998). Virion incorporation of human immunodeficiency virus type $1 \mathrm{Nef}$ is mediated by a bipartite membrane-targeting signal: analysis of its role in enhancement of viral infectivity. J. Virol. 72, 8833-8840.

Welker, R., Kottler, H., Kalbitzer, H. R., and Krausslich, H. G. (1996). Human immunodeficiency virus type 1 Nef protein is incorporated into virus particles and specifically cleaved by the viral proteinase. Virology 219, 228-236. doi: 10.1006/viro.1996.0240

Wildum, S., Schindler, M., Munch, J., and Kirchhoff, F. (2006). Contribution of Vpu, Env, and Nef to CD4 down-modulation and resistance of human immunodeficiency virus type 1 -infected T cells to superinfection. J. Virol. 80, 8047-8059. doi: 10.1128/JVI.00252-06

Williams, M., Roeth, J. F., Kasper, M. R., Filzen, T. M., and Collins, K. L. (2005). Human immunodeficiency virus type 1 Nef domains required for disruption of major histocompatibility complex class I trafficking are also necessary for coprecipitation of Nef with HLA-A2. J. Virol. 79, 632-636. doi: 10.1128/JVI.79.1.632-636.2005

Williams, M., Roeth, J. F., Kasper, M. R., Fleis, R. I., Przybycin, C. G., and Collins, K. L. (2002). Direct binding of human immunodeficiency virus type 1 Nef to the major histocompatibility complex class I (MHC-I) cytoplasmic tail disrupts MHC-I trafficking. J. Virol. 76, 12173-12184. doi: 10.1128/JVI.76.23.1217312184.2002
Xu, X. N., Laffert, B., Screaton, G. R., Kraft, M., Wolf, D., Kolanus, W., et al. (1999). Induction of Fas ligand expression by HIV involves the interaction of Nef with the T cell receptor zeta chain. J. Exp. Med. 189, 1489-1496. doi: 10.1084/jem.189.9.1489

Xu, X. N., Screaton, G. R., Gotch, F. M., Dong, T., Tan, R., Almond, N., et al. (1997). Evasion of cytotoxic T lymphocyte (CTL) responses by nef-dependent induction of Fas ligand (CD95L) expression on simian immunodeficiency virus-infected cells. J. Exp. Med. 186, 7-16. doi: 10.1084/jem.186.1.7

Yang, Y., Fricke, T., and Diaz-Griffero, F. (2013). Inhibition of reverse transcriptase activity increases stability of the HIV-1 core. J. Virol. 87, 683-687. doi: 10.1128/JVI.01228-12

Zazopoulos, E., and Haseltine, W. A. (1993). Effect of nef alleles on replication of human immunodeficiency virus type 1. Virology 194, 20-27. doi: $10.1006 /$ viro. 1993.1230

Zhou, H., Xu, M., Huang, Q., Gates, A. T., Zhang, X. D., Castle, J. C., et al. (2008). Genome-scale RNAi screen for host factors required for HIV replication. Cell Host Microbe 4, 495-504. doi: 10.1016/j.chom.2008.10.004

Zhou, J., and Aiken, C. (2001). Nef enhances human immunodeficiency virus type 1 infectivity resulting from intervirion fusion: evidence supporting a role for Nef at the virion envelope. J. Virol. 75, 5851-5859. doi: 10.1128/JVI.75.13.58515859.2001

Conflict of Interest Statement: The authors declare that the research was conducted in the absence of any commercial or financial relationships that could be construed as a potential conflict of interest.

Received: 19 March 2014; accepted: 30 April 2014; published online: 20 May 2014. Citation: Basmaciogullari S and Pizzato M (2014) The activity of Nef on HIV-1 infectivity. Front. Microbiol. 5:232. doi: 10.3389/fmicb.2014.00232

This article was submitted to Virology, a section of the journal Frontiers in Microbiology Copyright (c) 2014 Basmaciogullari and Pizzato. This is an open-access article distributed under the terms of the Creative Commons Attribution License (CC BY). The use, distribution or reproduction in other forums is permitted provided the original author(s) or licensor are credited and that the original publication in this journal is cited, in accordance with accepted academic practice. No use, distribution or reproduction is permitted which does not comply with these terms. 